\title{
RECONOCIMIENTO Y OBSERVACIONES BIONÓMICAS DE Sipha flava (HEMIPTERA: APHIDIDAE) ATACANDO EL PASTO KIKUYO EN DOS ZONAS DE COLOMBIA
}

\section{SURVEY AND BIONOMIC OBSERVATIONS OF Sipha flava DAMAGING KIKUYO GRASS IN TWO COLOMBIAN SITES}

\author{
Francisco J. Posada-Flórez ${ }^{1}$, Lorena Téllez-Farfán ${ }^{2}$, Ronald Simbaqueba ${ }^{3}$, Francisco Serna ${ }^{4}$
}

${ }^{1}$ Ing. Agrónomo. Entomólogo PhD., Investigador Científico Independiente, e-mail: fjavierposada@hotmail.com; ${ }^{2}$ Estudiante de pregrado de la Facultad de Ciencias Ambientales, Joven investigadora, Universidad de Ciencias Aplicadas y Ambientales U.D.C.A, Calle 222 No.55-30, Bogotá, D.C. Colombia, e-mail: tllezlorena@gmail.com; ${ }^{3}$ Estudiante de postgrado Facultad de Agronomía, Universidad Nacional de Colombia, carrera 30 \# 45-03, Bogotá D.C., e-mail: rons18@gmail.com; ${ }^{4}$ Ing. Agrónomo. M.Sc. Entomología, PhD. Profesor, Museo Entomológico UNAB, Facultad de Agronomía, Universidad Nacional de Colombia, carrera 30 \#45-03 Bogotá, D.C., Colombia, e-mail: fjsernac@unal.edu.co.

Rev. U.D.C.A Act. \& Div. Cient. 17(1): 95-104, Enero-Junio, 2014

\section{RESUMEN}

El áfido Sipha flava (Hemiptera: Aphididae), se encontró en pasto kikuyo, Pennisetum clandestinum, en el norte de la Sabana de Bogotá y en el área urbana de Manizales. Se evaluó el daño ocasionado por su alimentación y las características de las colonias. El amarillamiento de la hoja presentó un valor máximo de $31,3 \% / \mathrm{m}^{2}$. Las colonias de $S$. flava prefirieron el haz de la hoja y se ubicaron, mayormente, sobre la parte distal, donde se encontraron los síntomas. El máximo número de colonias por hoja fue de 17, las cuales, estaban constituidas por pocos individuos de adultos ápteros y ninfas. Los adultos alados no se observaron sobre el follaje, pero se encontraron en trampas amarillas, ubicadas en zonas cercanas a los sitios de muestreo. Las poblaciones de S. flava, se encontraron en sitios con plena radiación solar y en hábitats donde el pasto crecía espontáneamente: bordes de cercas, vías, prados de jardines o canchas deportivas. No se encontró S. flava ni síntomas del daño en otras plantas asociadas al kikuyo. La infestación por S. flava puede afectar la calidad forrajera, por lo que el manejo de este insecto debe enfocarse en las prácticas culturales, empleo de los enemigos naturales en programas de control biólogo y en buscar fuentes de resistencia varietal.

Palabras clave: Áfido, enemigos naturales, pasto, plantas hospedantes, síntoma de daño, relación planta-insecto.

\section{SUMMARY}

The aphid Sipha flava was found on kikuyu grass, Pennisetum clandestinum, in the Northern Sabana of Bogota and Manizales urban area. We evaluated the damage caused due to the aphid's feeding habits and colonies characteristics. Symptoms of yellow leaves reached the maximum value of $31.3 \% / \mathrm{m}^{2}$. Colonies of $S$. flava preferred the upper leaf feeding and were located in greater numbers on the distal part, where the symptoms were found. The maximum number of colonies found per leaf was 17 and they were composed by few individuals of apterous adults and nymphs. Alate adults were not found in the field but were found in yellow pan traps, located nearby to the field sample area. $S$. flava populations were found on kikuyu grass grown under full sun exposure and in habitats where this grass grows spontaneously, such as prairies, edges of roads, orchards, gardens, and sport fields. Neither $S$. flava nor the symptoms of its damage were present on other plants associated with kikuyu grass. The infestation by $S$. flava can affect the quality of forage and the management of this insect should focus on cultural practices, the use of natural enemies in biological control programs, and by searching for varietal resistance sources.

Key words: Aphid, natural enemies, grass, host plants, damage symptom, cattle, insect-plant relationship. 


\section{INTRODUCCIÓN}

En Colombia, se han registrado 13 especies de áfidos atacando gramíneas o Poáceas (Tabla 1) (Posada, 1989). Dentro de las especies de común ocurrencia en estas plantas, cabe destacar algunas, como Sipha flava Forbes (Hemiptera: Aphididae) y Melanaphis sacchari Zehntner (Hemiptera: Aphididae), que transmiten virus en gramíneas de granos, caña de azúcar y forrajes (Victoria et al. 1999; Comstock \&
Gilbert, 2009; Akbar et al. 2010). Algunas de estas especies de áfidos presentan distribución mundial, como Aphis gossypii Glover y Myzus persicae Sulzer, mientras que otras, como S. flava, vienen ampliando su rango de distribución y actuando como especies invasoras. Algunas presentan potencial de transmitir y de dispersar virus, lo que obliga a tomar medidas sanitarias y desarrollar programas de búsqueda de variedades resistentes, para reducir su impacto sobre la producción agrícola (Fukumoto \& Mau, 1989).

Tabla 1. Lista de áfidos que atacan gramíneas en Colombia (Posada, 1989).

\begin{tabular}{|c|c|c|c|}
\hline Nombre científico & Nombre común & Hospedante & Hábito \\
\hline Acyrthosiphon dirhodum (Walker & Pulgón de los cereales & $\begin{array}{l}\text { Avena, Maíz, Trigo, Ce- } \\
\text { bada }\end{array}$ & $\begin{array}{l}\text { Chupador follaje, } \\
\text { espigas }\end{array}$ \\
\hline Aphis gossypii Glover & Pulgón del algodonero & $\begin{array}{l}\text { Maíz, Pasto kikuyo, } \\
\text { pasto Brasilero }\end{array}$ & Chupador follaje, \\
\hline Asiphoniella dactylonii Theobald & & Pasto & Chupador follaje \\
\hline Macrosiphum avenae (F.) & Pulgón de la avena & $\begin{array}{l}\text { Avena, Pasto, Trigo, Ce- } \\
\text { bada pasto Brasilero }\end{array}$ & $\begin{array}{l}\text { Chupador follaje, } \\
\text { espigas, }\end{array}$ \\
\hline $\begin{array}{l}\text { Macrosiphum euphorbiae (Thom- } \\
\text { as) }\end{array}$ & Pulgón de la yuca & Pasto, Pasto brasilero & Chupador follaje, \\
\hline Melanaphis sacchari (Zehntner) & Pulgón de la caña & Caña de Azúcar & Chupador follaje \\
\hline Myzus persicae (Sulzer) & Pulgón verde de la papa & Avena Trigo, Cebada & $\begin{array}{l}\text { Chupador follaje, } \\
\text { espigas }\end{array}$ \\
\hline Rhopalosiphum maidis (Fitch) & Pulgón del maíz & $\begin{array}{l}\text { Caña de Azúcar, Maíz, } \\
\text { Pasto, Sorgo, Trigo, } \\
\text { Cebada }\end{array}$ & $\begin{array}{l}\text { Chupador follaje, } \\
\text { Chupador flores, } \\
\text { Chupador follaje, } \\
\text { Pasto rescate }\end{array}$ \\
\hline Rhopalosiphum padi (L.) & & $\begin{array}{l}\text { Arroz, Maíz, Trigo, Ce- } \\
\text { bada }\end{array}$ & Chupador follaje \\
\hline $\begin{array}{l}\text { Rhopalosiphum rufiabdominalis } \\
\text { (Sasaki) }\end{array}$ & $\begin{array}{l}\text { Pulgón rojizo de la raíz del } \\
\text { arroz }\end{array}$ & Arroz, Trigo, Cebada & Chupador raíces \\
\hline Sipha flava (Forbes) & Pulgón amarillo de la caña & $\begin{array}{l}\text { Arroz, Caña de Azúcar, } \\
\text { Maíz, Pasto, Sorgo, } \\
\text { Trigo, Cebada, kikuyo, } \\
\text { pasto brasilero }\end{array}$ & Chupador follaje, \\
\hline $\begin{array}{l}\text { Tetraneura nigriabdominalis Sa- } \\
\text { saki }\end{array}$ & $\begin{array}{l}\text { Pulgón negro de la raíz de } \\
\text { pasto }\end{array}$ & Pasto kikuyo & Chupador raiz, \\
\hline Toxoptera graminum (Rondani) & Pulgón de las gramíneas & Caña de Azúcar, Sorgo & Chupador follaje \\
\hline
\end{tabular}

S. flava, se conoce con el nombre común de "áfido amarillo de la caña de azúcar". Es originario de la región Paleártica, de donde se ha distribuido a la región Neotropical. Inicialmente, fue descrito sobre sorgo, en Illinois (USA) y su distribución abarca el continente americano, desde el norte de Estados Unidos hasta Argentina, incluyendo, el Caribe. En el Pacífico, se encuentra hasta Hawái (Fukumoto \& Mau, 1989; González et al. 1998; Butus et al. 2002; Hentz \& Nuessly, 2004).

El áfido es vector del virus del mosaico amarillo de la caña de azúcar (VMACA). Este áfido, se presenta en diferentes plantas hospedantes, especialmente gramíneas. S. flava y el VMACA 
se han encontrado en Luisiana y La Florida (USA) (Comstock \& Gilbert, 2009). En Colombia, aún no se ha registrado este virus en caña de azúcar.

En Colombia, S. flava se ha registrado alimentándose de follaje de pastos con distribución tanto en zonas de clima cálido, donde ataca cultivos de Andropogon gayanus (Calderón \& Varela, 1982), como en clima frío sobre pasto kikuyo (Posada, 1989). Adicionalmente, este áfido se ha registrado en gramíneas silvestres en Chile (González et al. 1998) y en Cynodon dactylon, empleado como césped en campos deportivos, en Argentina (Butus et al. 2002). También, se ha registrado en Hawái sobre pasto kikuyo, Pennisetum clandestinum, donde el daño tiene alta severidad (Fukumoto \& Mau, 1989).

El kikuyo es una especie introducida en Colombia (Patiño, 1969). Este pasto, se ha adaptado y desarrollado bien en suelos de clima medio y frío, donde ha llegado a ser la especie de gramínea predominante y se comporta como invasiva en los humedales, páramos, canales de riego y drenaje. Es una especie que se ha convertido en maleza, porque cubre prados y suelos agrícolas, donde su manejo exige gran esfuerzo, para evitar la competencia con las especies cultivadas (Labrada et al. 1996; Fernández-Alonso \& Rivera-Díaz, 2006; Hernández \& Rangel, 2009). Uno de los aspectos positivos de esta especie es su hábito de crecimiento, que contribuye al manejo y a la conservación de suelo, para evitar la erosión (Rivera-Posada, 1998). En ganadería es bien estimado como forraje, ya que tiene un alto vigor; es palatable para rumiantes y permite obtener una alta capacidad de carga de cabezas de ganado por hectárea, si se usan sistemas de manejo de pastoreo, de fertilización y de asociación con leguminosas (Ardila, 1980; Correa et al. 2008). Se estima que el $80 \%$ de las praderas bien establecidas del trópico alto colombiano, dedicadas a lechería, está conformado por este pasto (Mojica et al. 2009).

Respecto a los enemigos naturales de $S$. flava, se han realizado reconocimientos en cultivos de caña de azúcar, donde se registran, mayormente, especies de insectos depredadores, pertenecientes a las familias Coccinellidae (Coleoptera), Syrphidae (Diptera), Chrysopidae (Neuroptera) y Forficulidae (Dermaptera), que regulan naturalmente las poblaciones en campo (Gómez \& Lastra, 1995; Mendoza et al. 2006; Nuessly, 2011; Bustillo, 2013). En Colombia, en cultivos de caña de azúcar, se recomienda la liberación de varias especies de Chrysoperla (Neuroptera: Chrysopidae), para contribuir a regular las poblaciones de $S$. flava, cuando se detectan las infestaciones (Cenicaña, 2013).

Las plagas y las enfermedades afectan la calidad de los pastos y su manejo incluye la aplicación de plagicidas, lo que ha generado problemas de salud pública y contaminación ambiental (Jeyaratnam, 1990; Edwards, 1993). Debido a lo anterior y con el propósito de contribuir a la solución de los problemas sanitarios de campo, los objetivos de este trabajo fueron determinar y describir la especie del áfido que causa el amarillamiento y el secamiento de la hoja del pasto kikuyo, registrar y caracterizar su presencia en las hojas de esta especie vegetal en una zona del norte de Bogotá y en Manizales $\mathrm{y}$ reconocer sus enemigos naturales.

\section{MATERIALES Y MÉTODOS}

Se realizaron observaciones sobre prados y potreros, con pasto kikuyo, como especie dominante, en el norte de la ciudad de Bogotá y en la zona urbana de Manizales, para determinar áreas afectadas, por la presencia del áfido S. flava. En los recorridos, se recolectó follaje del pasto, para evaluar el daño y tomar muestras de los áfidos, los cuales, se trasladaron al laboratorio de entomología de la U.D.C.A, para realizar su determinación, obtener los adultos y reconocer la presencia de enemigos naturales. Muestras adicionales de los áfidos se depositaron en la colección taxonómica central (CTC) del Museo entomológico de la Facultad de Ciencias Agrarias de la Universidad Nacional de Colombia, sede Bogotá (UNAB).

Los reconocimientos para la evaluación de la infestación y daño, se realizaron en junio, julio y agosto del 2012, en predios de la Universidad de Ciencias Aplicadas y Ambientales U.D.C.A, al norte de la ciudad de Bogotá, Colombia (447’57”N, 7402'40”W), a $2570 \mathrm{msnm}$, con precipitación media de 1200 mm/año (Estupiñán \& Cabrera, 2008). Los reconocimientos en Manizales, se hicieron en prados y orillas de vías, en julio del 2012, a alturas comprendidas entre los 1.900 y 2.200 msnm, para establecer el organismo que estaba asociado con el amarillamiento del pasto kikuyo.

Para estimar la población de áfidos y el daño en los lotes con infestación y con daño, se lanzó al azar un marco de un metro cuadrado, para establecer la parcela de muestreo (Chalmers \& Parker, 1989). En cada lote, por muestreo, se tomaron cuatro sitios como réplicas. En cada parcela, se estimó el porcentaje de área cubierta con pasto kikuyo, con presencia de daño de los áfidos. De esta misma área, se tomaron al azar 10 hojas con síntomas de daño y, en cada hoja, se estableció el tipo de daño, discriminando entre sólo amarillamiento o amarillamiento con secamiento de la punta. Además, se determinó la parte de la hoja que presentaba los síntomas de daño y el número de la hoja en la planta que se encontraba amarilla, la cual, se contabilizó de forma alterna desde la parte terminal hacia la base (Figura 1 O). Adicionalmente, se contabilizó el número de colonias del áfido por el haz o envés y se tuvo en cuenta la localización de las colonias, si se encontraban en la parte de la hoja con o sin daño. Además, dentro del marco, se estableció la presencia 
de otra vegetación y si estas plantas presentaban colonias de S. flava o síntomas del daño por alimentación.

Los datos de conteo de áfidos, se analizaron con estadísticas descriptivas y se realizó análisis de varianza del daño y del número de colonias. Los resultados, se analizaron estadísticamente, con un nivel de significancia del 95\% (SAS Institute Inc., 2006). Se tomaron fotografías que documentan los estados del áfido, los síntomas de daño y los enemigos naturales, para facilitar el posterior reconocimiento en campo.

\section{RESULTADOS Y DISCUSIÓN}

Identificación. El áfido, se determinó como S. flava (Forbes 1884), por las características morfológicas, siguiendo las claves para especímenes vivos y preparados en montajes (Simbaqueba et al. en prensa). Además, se tuvo en cuenta los hábitos de alimentación descritos ampliamente en la literatura para el reconocimiento del daño y los síntomas que causa en la planta hospedante (Stoetzel, 1987; Teetes \& Pendleton, 2000).

Descripción de especímenes vivos de S. flava. Todos los estados alados y ápteros son de color amarillo o verde claro y tienen el cuerpo cubierto por setas. El aparato bucal alcanza las coxas medias. La cabeza y el pronoto son de color negro dividido dorsalmente por una línea de color claro, que se extiende hasta la parte posterior del abdomen. Éste es de color amarillo y en la parte dorsal presenta puntos negros, que conforman seis líneas longitudinales, dos mediales, dos pleurales y dos laterales. Los sifúnculos son cortos, escasamente se observan a simple vista y son de color marrón. La cauda es corta y semicircular. Las patas son de color oscuro con los tarsos negros (Stoetzel, 1987; Teetes \& Pendleton, 2000) (Figura 1 A, B).

Descripción de especímenes curados de $S$. flava. (No. de catálogo 592, Museo UNAB). Cuerpo alargado de 1,3$1,9 \mathrm{~mm}$ de largo. Antenas de cinco segmentos, casi de la mitad del largo del cuerpo, proceso terminal aproximadamente el doble de su respectivo segmento. Rostro hasta la coxa media, último segmento rostral casi de la mitad del largo del segmento II del tarso posterior. Dorso membranoso, casi liso. Setas dorsales gruesas. Sifúnculos en forma de conos cortos. Primeros segmentos tarsales con 5 setas. Alados con escleritos laterales en los segmentos II-IV y VI-VII, algunos más pequeños en el segmento V. Rinarios secundarios en número de 2-5 situados en el segmento III (Figura 1 C, D, E).

Plantas hospedantes. S. flava, se registró solamente atacando el pasto kikuyo, aunque otras gramíneas, como falsa poa (Holcus lanatus L.) y ryegrass (Lolium perenne L.), estaban creciendo asociadas en el mismo sitio. Tampoco se encontró atacando plantas de hoja ancha que crecían cercanas al pasto kikuyo. En Colombia, también se ha registrado como plantas hospedantes el pasto brasilero (Phalaris azudinacea L.) y el pasto llanero (Andropogon gayanus Kunth) (Calderón \& Varela, 1982; Posada 1989) (Tabla 1).

Distribución. S. flava, se registró en la Sabana de Bogotá, atacando pasto kikuyo en canchas de fútbol, parques, potreros, bordes de vías y cercas expuestas a la radiación solar directa. En el área urbana de Manizales, se observó en prados y en las orillas de las vías, donde el kikuyo se encontraba creciendo, como especie dominante. La distribución de $S$. flava en Colombia, abarca desde bajas elevaciones, zonas cálidas, donde se cultiva arroz y caña de azúcar, entre otras, hasta elevadas altitudes donde se cultiva cebada y trigo (Posada, 1989) (Tabla 1).

Hábitos y comportamiento. En pasto kikuyo, S. flava forma colonias distribuidas en grupos poco numerosos, que se localizan, generalmente, sobre el haz de las hojas y se distribuyen, tanto en la parte con síntomas de amarillamiento como en la parte de la hoja que aún está verde. El total de colonias, se estimó sumando el número de colonias presentes en el haz y en el envés (Tabla 2). En las evaluaciones, el mayor promedio de colonias, se encontró en agosto, tanto en el haz (3,5 \pm $0,5)$ como en el envés $(0,8 \pm 0,2)$. En junio y julio, se hallaron sobre el haz $1,9 \pm 0,3$ y $2,4 \pm 0,3$ colonias respectivamente, mientras que en el envés se registró para ambos meses 0,3 \pm 0,1 colonias. Estos resultados son contrarios a lo registrado en caña de azúcar y en otras plantas hospedantes, donde se indica que la mayor cantidad de áfidos se presenta en el envés de la hoja (Gómez \& Lastra, 1995; González et al. 1998; Butus et al. 2002). Igualmente, son contrarios a los registros que indican que se presenta en colonias numerosas que cubren la hoja y puede estar asociado con otras especies de áfidos, como M. sacchari (Nuessly, 2011).

Las ninfas y los adultos ápteros de S. flava son poco móviles, generalmente, permanecen quietos con las antenas orientadas hacia atrás, a pesar de que se disturben. Cuando se colectaron las muestras de hojas, las colonias no se disturbaron como sí lo hacen otras especies de áfidos. En las colonias no se observó presencia de adultos alados y éstos solamente se obtuvieron cuando se tomaron colonias de ápteros y se llevaron al laboratorio, donde se alimentaron con follaje de pasto kikuyo y en trampas amarillas que se ubicaron en los bordes de los lotes, cubiertos con este pasto, donde se realizó la evaluación. En estas trampas, se capturaron unos pocos adultos en comparación con la captura de hasta cien especímenes de otros áfidos en avaluaciones semanales. Los ataques sobre el pasto kikuyo, se observaron en áreas abiertas con exposición directa al sol. En los sitios con sombrío de árboles, no se encontró la presencia de los áfidos o follaje con síntomas de amarillamiento, que es el síntoma de daño característico, que causa la alimentación S. flava. 

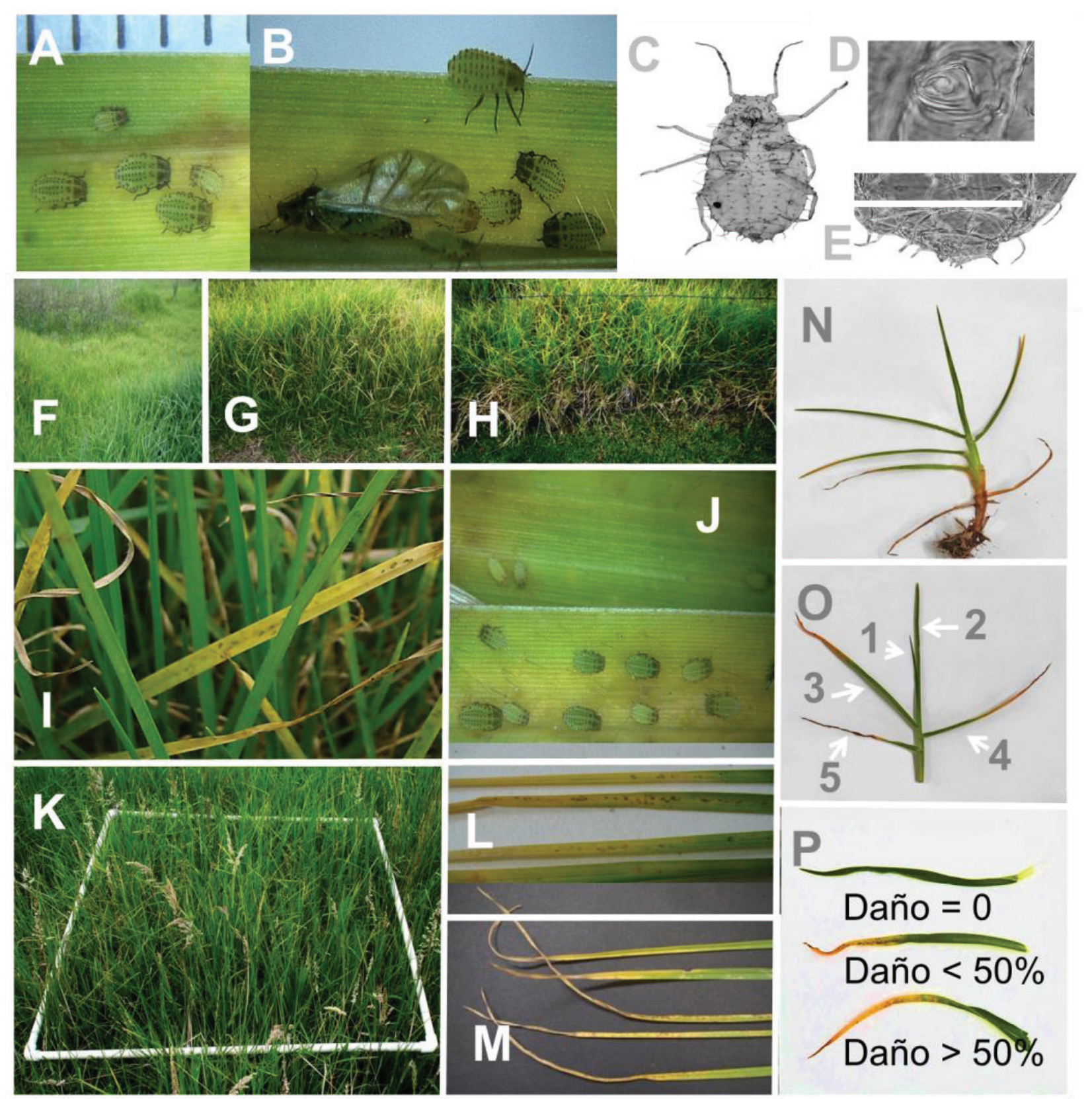

Figura 1. Características morfológicas de los adultos y ninfas de Sipha flava. A, B. Adultos y ninfas alimentándose sobre pasto kikuyo. C, D, E. Espécimen montado en placas. C. Características del adulto. D. Sifúnculo. E. Cauda. F, G, H. Vista de una pradera con daño causado por $S$. flava sobre pasto Kikuyo con síntomas de amarillamiento de la hoja por el daño de alimentación de S. flava. I, J. Plantas mostrando los síntomas del daño característico de amarillamiento del follaje en el campo causado por la alimentación de S. flava y localización de la colonia sobre el haz de la hoja. K. Marco para evaluar por metro cuadrado la infestación y los síntomas del daño de las colonias de S. flava. L. Hojas con diferente intensidad de los síntomas del daño amarillamiento de la hoja. M. Hojas del pasto kikuyo con secamiento de la punta de la hoja por daño de S. flava. N, y O. Planta de kikuyo con el patrón de daño en las hojas. P. Escala de evaluación del daño en pasto kikuyo. 
Tabla 2. Porcentaje promedio de colonias del áfido S. flava sobre el haz, envés y total de las hojas del pasto kikuyo, encontradas en una muestra de diez hojas tomadas al azar por metro cuadrado, en cuatro parcelas por cada mes evaluado.

\begin{tabular}{|l|l|l|l|l|l|l|l|l|l|l|}
\hline \multirow{2}{*}{ Evaluación } & & \multicolumn{3}{|c|}{ Colonia haz } & \multicolumn{3}{c|}{ Colonia envés } & \multicolumn{3}{c|}{ Colonia total } \\
\cline { 3 - 11 } & N & Media \pm E.E. & $\begin{array}{l}\text { Míni- } \\
\text { mo }\end{array}$ & $\begin{array}{l}\text { Máxi- } \\
\text { mo }\end{array}$ & Media \pm E.E. & $\begin{array}{l}\text { Míni- } \\
\text { mo }\end{array}$ & $\begin{array}{l}\text { Máxi- } \\
\text { mo }\end{array}$ & Media \pm E.E. & $\begin{array}{l}\text { Míni- } \\
\text { mo }\end{array}$ & \begin{tabular}{l} 
Máximo \\
\hline Junio
\end{tabular} \\
\hline Julio & 4 & $1,9 \pm 0,3 \mathrm{~B}$ & 0 & 8 & $0,3 \pm 0,1 \mathrm{~A}$ & 0 & 2 & $2,2 \pm 0,4 \mathrm{~B}$ & 0 & 10 \\
\hline Agosto & 4 & $2,4 \pm 0,3 \mathrm{AB}$ & 0 & 8 & $0,3 \pm 0,1 \mathrm{~A}$ & 0 & 2 & $2,7 \pm 0,4 \mathrm{~B}$ & 0 & 10 \\
\hline
\end{tabular}

* $\mathrm{N}=$ repetición y cada repetición tuvo diez muestras. En total se evaluaron 40 hojas por muestreo en cuatro metros cuadrados.

** Promedios seguidos por la misma letra no presentaron diferencias significativas.

Estadísticas de las colonias sobre el haz $\mathrm{GL}=2,11, \mathrm{~F}=0.09, \mathrm{P}=0.9120$, de las colonias sobre el envés $\mathrm{GL}=2,11, \mathrm{~F}=0.09$, $\mathrm{P}=0.9120$ y del total de colonias en las hojas $\mathrm{GL}=2,11, \mathrm{~F}=9.33, \mathrm{P}=0.0064$.

De acuerdo con el manejo del pasto kikuyo, S. flava y los síntomas de amarillamiento del follaje, se presentaron en pastos utilizados para el pastoreo y en canchas deportivas, donde se emplea como césped. Adicionalmente, se encontró en los bordes de potreros y junto a las cercas, donde el kikuyo amontona en matojos (Figura $1 \mathrm{~F}-\mathrm{H}$ ). Los sitios sin manejo del pasto actuaron como focos de infestación para prados o praderas, que recibieron corte o pastoreo de animales, en los cuales, a medida que el pasto empezó a crecer se observaron los síntomas de hoja amarilla y colonias poco numerosas de los áfidos.

Evaluación de daño y muestreo. Los síntomas del daño de alimentación se encuentran en las hojas del kikuyo, donde se presentan los áfidos y, en los sitios de alimentación, se observaron áreas necróticas con clorosis (Figura $1 \mathrm{~J}$ ). En las hojas donde empieza la colonización de los áfidos, se observó la presencia de puntos amarillos que se extendieron sobre toda la lámina foliar, avanzando desde la parte terminal hacia la base de la hoja. En las hojas del kikuyo, donde se establecen las colonias del áfido, el daño se hizo más severo, a medida que avanzó el amarillamiento, ya que se seca la punta de la hoja (Figura 1 I, L, M). Los síntomas del daño en otros cultivos, como sorgo y caña de azúcar, se manifiestan como color rojizo en las hojas (Gómez \& Lastra, 1995), lo cual, se reconoce como una respuesta de resistencia de la planta al daño de alimentación de los áfidos; sin embargo, en kikuyo no se observaron coloraciones diferentes al amarillamiento (Costa-Arubulú et al. 2001).

En las plantas con colonias de S. flava, se encontró escasa producción de miel de rocío y no se observó desarrollo o acumulación de fumagina, ni presencia de hormigas en simbiosis con los áfidos. Igualmente, este fenómeno ha sido registrado en cultivos de caña de azúcar del Valle del Cauca (Gómez \& Lastra, 1995).
S. flava, se encontró atacando en todos los estados de desarrollo del pasto kikuyo. La presencia del áfido se puede reconocer a distancia por el daño, ya que el pasto presenta, inicialmente, follaje con color amarillo y, en la medida que se intensifica el daño, las hojas se tornan de color pajizo, que da la apariencia de secamiento de las hojas de la planta déficit hídrico (Figura 1 F, G, H, I, L - P) (Fukumoto \& Mau, 1989).

La mayor población de colonias de áfidos, se encontró en agosto, tanto en el haz como en el envés. En este mes, también se halló el máximo número de colonias por hoja: trece en el haz y siete en el envés, con un máximo de 17 colonias por hoja. Los resultados presentaron diferencias significativas para las colonias encontradas sobre el haz y para el total por hoja, pero no para las encontradas sobre el envés (Tabla 2).

Los síntomas de amarillamiento en la planta, se observan desde la parte basal a terminal, lo que demuestra que, a medida que la planta genera nuevas hojas, los áfidos las colonizan. El síntoma de punta seca ocurre después que los áfidos se alimentan y la hoja presenta el amarillamiento (Figura 1 L - P). La observación del síntoma de amarillamiento, generalmente, correspondió a la tercera hoja, a partir de la parte terminal (Figura 1 O), con valores en junio, de $77,5 \%$; en julio, de $60 \%$ y, en agosto, de $47,5 \%$ ( $n=40$ para cada mes). Los mismos síntomas en la segunda hoja alcanzaron valores de $12,5 \%, 37,5 \%$ y $45,0 \%$, respectivamente, para los mismos meses. En la cuarta hoja, estos síntomas tuvieron valores de $10,5 \%, 2,5 \%$ y $7,5 \%$, respectivamente, para los meses evaluados y las hojas a este nivel presentaron la mayor intensidad de punta seca (Figura 10 ).

En las evaluaciones por cuadrante en junio, julio y agosto, en la U.D.C.A, se encontró, respectivamente, un porcentaje promedio (media \pm error estándar), de 28,8 $\pm 11,4,20,0 \pm$ 
12,2 y 31,3 $\pm 10,8$, del área cubierta con síntomas de hoja amarilla. Los resultados indicaron que la intensidad de los síntomas de daño fue moderada; sin embargo, en algunas áreas, el pasto se observó completamente amarillo y finalmente seco (Figura $1 \mathrm{~F}$ - I).

Sobre las diez muestras de hoja con síntomas de amarillamiento, tomadas por cuadrante al azar, se encontró que los síntomas de amarillamiento varían de acuerdo con la evaluación por mes. El síntoma de amarillamiento, menor del 50\% de la hoja, tuvo su mayor valor en julio, con el $82,5 \pm 11,8 \%$ del total de las muestras de este mes, mientras que en junio y agosto, los valores fueron $77,5 \pm 4,8 \%$ y $77,5 \pm 2.5 \%$, respectivamente. El síntoma de amarillamiento, mayor del $50 \%$ de la longitud de la hoja, alcanzó valores inferiores al 22.5 $\pm 10,3 \%$ para los tres meses (Tabla 3, Figura 1P).
En relación con los síntomas de amarillamiento de las hojas el mayor porcentaje alcanzó un valor promedio de $87,5 \pm$ $2,5 \%$ en el mes de junio (). Los resultados para los meses evaluados presentaron diferencias significativas $(\mathrm{GL}=2,11$, $\mathrm{F}=9$, 33, $\mathrm{P}=0$,0064) (Tabla 2). El síntoma de daño de la punta de la hoja seca mostró que se inicia simultáneamente con el desarrollo del síntoma de hoja amarilla, los cuales, aparecen tan pronto como las colonias del áfido empiezan a alimentarse. Este síntoma en la hoja presentó una relación directa con la intensidad del amarillamiento de la hoja y la respuesta está asociada con el daño de alimentación; sin embargo, la intensidad puede estar influenciada por factores, como las condiciones ambientales o las prácticas de manejo de la pradera y el número o posición de la hoja evaluada en la planta.

Tabla 3. Porcentaje promedio de los síntomas amarillamiento y punta seca de la hoja del pasto kikuyo causado por la alimentación del áfido S. flava, sobre una muestra de diez hojas tomadas al azar por metro cuadrado, en cuatro parcelas por mes evaluado.

\begin{tabular}{|l|c|c|c|c|}
\hline \multirow{2}{*}{ Evaluación } & \multirow{2}{*}{$N^{*}$} & \multicolumn{2}{|c|}{ Síntoma de la hoja amarilla } & \multirow{2}{*}{ Punta de la hoja seca } \\
\cline { 3 - 4 } & & Menor 50\% de la hoja & Mayor 50\% de la hoja & \\
\cline { 3 - 4 } & & Media \pm E.E. & Media \pm E.E. & Media \pm E.E. \\
\hline Junio & 4 & $77,5 \pm 10,3 \mathrm{~A}$ & $22,5 \pm 10,3 \mathrm{~A}$ & $87,5 \pm 2,5 \mathrm{~A}$ \\
\hline Julio & 4 & $82,5 \pm 11,8 \mathrm{~A}$ & $17,5 \pm 11,8 \mathrm{~A}$ & $72,5 \pm 2,5 \mathrm{~B}$ \\
\hline Agosto & 4 & $77,5 \pm 4,8 \mathrm{~A}$ & $22,5 \pm 4,8 \mathrm{~A}$ & $77,5 \pm 2,5 \mathrm{~B}$ \\
\hline
\end{tabular}

* $\mathrm{N}=$ repetición y cada repetición tuvo diez muestras. En total se evaluaron 40 hojas por muestreo en cuatro metros cuadrados.

** Promedios seguidos por la misma letra no presentaron diferencias significativas.

Estadísticas de los síntomas de hoja amarilla en menos del $50 \%$ de la hoja $\mathrm{GL}=2,11, \mathrm{~F}=0.09, \mathrm{P}=0.9120$, en más del $50 \%$ dela hoja $\mathrm{GL}=2,11, \mathrm{~F}=0.09, \mathrm{P}=0.9120$ y de la punta seca de la hoja $\mathrm{GL}=2,11, \mathrm{~F}=9.33$, $\mathrm{P}=0.0064$.

Los resultados de los síntomas del amarillamiento y punta seca sobre las hojas terminales permiten establecer la dinámica de la intensidad del daño, como respuesta a la presencia de las colonias de los áfidos y a la actividad de alimentación; así, si las hojas terminales presentan daño, seguramente el resto de las hojas basales ya han sido atacadas por las colonias del áfido. Además, estos síntomas se pueden utilizar para reconocer y detectar, oportunamente, el daño y la presencia de $S$. flava, atacando el pasto kikuyo en las praderas.

Enemigos naturales. En condiciones de campo, atacando las ninfas de $S$. flava, se reconoció la presencia de seis enemigos naturales: cinco depredadores y un hongo entomopatógeno. El grupo de los depredadores estuvo conformado por cuatro especies de la familia Coccinellidae (Coleoptera) y una especie de mosca de la familia Syrphidae (Diptera). Estos depredadores, se encontraron en campo y se trasladaron al laboratorio, donde completaron su ciclo de vida siendo alimentados con ninfas de S. flava. Aparte de Coccinélidos y Sírfidos, Nuessly (2011) menciona algunos géneros de hormigas, de tijeretas, de avispas e, incluye a las arañas, como controladores importantes de las poblaciones de S. flava. El hongo entomopatógeno Erynia (Entomophthorales), se encontró atacando las ninfas. En relación con parasitoides, no se encontraron atacando $S$. flava, a pesar de que se presentan como el mayor grupo de enemigos naturales de los áfidos y que se hallaron en el área de estudio, atacando a otros áfidos en diferentes plantas, dentro del mismo hábitat del pasto kikuyo afectado por S. flava. Esto coincide con Hentz \& Nuessly (2004), quienes indican que en S. flava no se ha registrado el ataque de parasitoides. 
Se requiere hacer más investigación para determinar exactamente el potencial de los controladores poblacionales de S. flava y adelantar estudios para conocer los aspectos de la biología, ecología, capacidad de control de las especies encontradas y determinar las que se pueden criar en laboratorio. A partir de esto, se pueden desarrollar técnicas de producción masiva en el caso de que se puedan utilizar como controladores biológicos en campo.

Manejo de S. flava. Los ganaderos que utilizan el pasto kikuyo para la alimentación animal deben prestar atención al daño causado por S. flava. Se desconocen los factores que estimulan la explosión de las poblaciones de este áfido en pasto kikuyo. El daño que se observó puede ser considerable, debido al amarillamiento y el secamiento de las hojas, lo que puede hacer perder la palatabilidad, disminuir el valor nutricional del forraje y, por ende, afectar la producción animal.

Se debe tener en cuenta que los pastos son un cultivo y que se requiere cuidar de los aspectos sanitarios y diseñar programas de manejo integrado. En cuanto al daño que causa S. flava, se debe evaluar el efecto sobre la calidad del follaje, para establecer las estrategias de manejo. Se sugiere que se determine el efecto del pastoreo y del manejo de los enemigos naturales antes de iniciar la aplicación generalizada de plaguicidas, los cuales, como se ha demostrado en pastos de clima frio y medio, no han sido eficaces para manejar el daño de Collaria sp. (Hemiptera: Miridae), por el contrario, han estimulado la explosión de sus poblaciones (Bernal, 1994; Garza \& Barreto, 2011). Adicionalmente, la aplicación frecuente de plaguicidas en el agroecosistema lechero ha permitido documentar el efecto de los insecticidas sobre la salud animal, humana y el impacto sobre el medio ambiente (Márquez et al. 2010; Morales et al. 2010), por lo que no se aconseja que el manejo de $S$. flava siga el mismo esquema de manejo de la chinche de los pastos.

Conflicto de intereses: El manuscrito fue preparado y revisado con la participación de todos los autores, quienes declaramos que no existe ningún conflicto de intereses que ponga en riesgo la validez de los resultados presentados.

\section{BIBLIOGRAFÍA}

1. ARDILA V., J. 1980. Colombia. Programa de investigación en pastos tropicales. En: Análisis de la cooperación entre los centros nacionales y los centros internacionales de investigación agropecuaria. Versión Preliminar. IICA_OEA. Proyecto cooperativo de investigación sobre tecnología agropecuaria en América Latina "PROTAAL". Disponible desde internet en: http://books.google.com/books (con acceso 03/25/2013).
2. AKBAR, W.; SHOWLER, A.T.; REAGAN, T.E.; WHITE, W.H. 2010. Categorizing Sugarcane Cultivar Resistance to the Sugarcane Aphid and Yellow Sugarcane Aphid (Hemiptera: Aphididae). J. Econ. Entomol. 103(4):1431-1437.

3. BERNAL E., J. 1994. Control de plagas y enfermedades. Cap. 10. En: Pastos y forrajes tropicales: producción y manejo. Bogotá D. C. Banco Ganadero. 3ra edición. 575p.

4. BUSTILLO, A. 2013. Insectos plaga y organismos benéficos del cultivo de la caña de azúcar en Colombia. Cenicaña. Cali. 164p.

5. BUTUS, M.L.; SALUSO, A.; FORMENTO, N. 2002. Nuevo hospedante para el "pulgón amarillo de la caña de azúcar" Sipha flava (Hemiptera: Aphididae) en Argentina. Rev. Cient. Agropec. 6:57-59.

6. CALDERÓN, M.; VARELA, F.A. 1982. Descripción de las plagas que atacan los pastos tropicales y características de sus daños. Guía de Estudio. Unidad Audio tutorial Centro Internacional de Agricultura Tropical. Cali. Colombia. 52p.

7. CENICAÑA. 2013. Pulgón amarillo de la caña. Sanidad vegetal. Plagas. Disponible desde Internet en: http:// www.cenicana.org/investigacion/variedades/sanidad_vegetal.php?opcion $=2 \& o p c i o n 2=4$ (con acceso $11 / 03 / 2013$ ).

8. CHALMERS, N.; PARKER, P. 1989. The OU Project Guide. Fieldwork and Statistic for Ecological Projects, 2nd edn. Open University and Field Studies Council, Dorset. 108p.

9. COMSTOCK, J.C.; GILBERT, R.A. 2009. Sugarcane Mosaic Virus Disease. UF University of Florida .IFAS Extension. 3p.

10. CORREA, C.; PABÓN R.; CARULLA, F. 2008. Valor nutricional del pasto kikuyo (Pennisetum clandestinum Hoechst Ex Chiov) para la producción de leche en Colombia (Una revisión): I - Composición química y digestibilidad ruminal y posruminal. Livestock Research for Rural Development. 20 (59) Disponible desde internet en: http://www.Irrd.org/lrrd20/4/corra20059.htm (con acceso 03/25/2013).

11. COSTA-ARUBULÚ, C.; GIANOLI, E.; GONZALES, W.L.; NIEMEYER, H.M. 2001. Feeding by the aphid Sipha flava produces a reddish spot on leaves of Sorghum 
halepense: an induced defense? J. Chem. Ecol. 27:273-283.

12. EDWARDS, C.A. 1993. The impact of pesticides on the environment. En: Pimentel, D.; Lehman, H. (eds.). The pesticide Question, Environment, Economics, Ethics. Routledge Chapman \& Hall, Inc. United States of America. 441p.

13. ESTUPIÑÁN, L.H.; CABRERA, L.M. 2008. Los alrededores: todo un ambiente en la U.D.C.A. Rev. U.D.C.A Act. \& Div. Cient. 11(2):3-9.

14. FERNÁNDEZ-ALONSO, J.L.; RIVERA-DÍAZ, O. 2006. Las Labiadas. Instituto de Ciencias Naturales - Universidad Nacional de Colombia sede Bogotá. p. 385679.

15. FUKUMOTO, G.; MAU, R. 1989. Yellow sugarcane aphid in Hawayan pastures, HITAHR BR EF 081-11/89. 2p.

16. GARZA, P.; BARRETO, T. 2011. Fluctuación temporal de la chinche de los pastos Collaria scenica (Stal, 1859) (Hemiptera: Heteroptera: Miridae) en la Sabana de Bogotá. Universidad Militar Nueva Granada. Rev. Fac. Cienc. Bás. 7(2):166-179.

17. GÓMEZ, L.; LASTRA, B. 1995. Los insectos asociados con la caña de azúcar en Colombia. En: Cenicaña. El cultivo de la caña en la zona azucarera de Colombia. Cali, CENICANA. p.237-263.

18. GONZÁLEZ, W.; FUENTES-CONTRERAS, E.; NIEMEYER, H.M. 1998. Una nueva especie de áfido (Hemiptera: Aphididae) detectada en Chile: Sipha flava (Forbes). Rev. Chilena Entomol. 25:87-90.

19. HENTZ, M.; NUESSLY, G. 2004.Development, longevity, and fecundity of Sipha flava (Homoptera: Aphididae) feeding on Sorghum bicolor. Environ. Entomol. 33(3):546-553.

20. HERNÁNDEZ, R.; RANGEL, CH. 2009. La vegetación del humedal de Jaboque. (Bogotá, D.C.). Caldasia. 31(2):355-379.

21. JEYARATNAM, J. 1990. Acute pesticide poisoning: a major global health problem. World Health Statistics Quarterly. 43(3):139-144.

22. LABRADA, R.; CASELEY, J.C.; PARKER, C. 1996. Manejo de Malezas para Países en Desarrollo. (Estudio FAO Producción y Protección Vegetal - 120). Dispo- nible desde Internet en: http://www.fao.org/docrep/ T1147S/t1147s08.htm (con acceso 25/03/2013).

23. MÁRQUEZ, S.; MOSQUERA, R.; HERRERA, M.; MONEDERO, C. 2010. Estudio de la absorción y distribución del clorpirifos en plantas de pasto Kikuyo (Pennisetum clandestinum Hochst ex Chiov.) cultivadas hidropónicamente. Rev. Col. Cienc. Pec. 23:158165.

24. MENDOZA, J.; GUALLE, D., GÓMEZ, P.; JUNCO, J. 2006. Enemigos naturales del áfido amarillo, Sipha flava Forbes. En: Carta Informativa CINCAE. 8(1):8.

25. MOJICA, J.; CASTRO, E.; LEÓN, J.; CÁRDENAS, E.A.; PABÓN, M.L.; CARULLA, J.E. 2009. Efecto de la oferta de pasto kikuyo (Pennisetum clandestinum) sobre la producción y calidad composicional de la leche bovina. Livestock Res. Rur.l Developm. 21(01). Disponible desde internet en: http://www.corpoica. org.co/SitioWeb/Archivos/oferta/articulooferta.pdf (con acceso 25/2013).

26. MORALES, V.; RODRÍGUEZ O., N.; RESTREPO B., L.F.; LÓPEZ C., C. 2010. Relación entre residuos de clorpirifos en leche y sangre de vacas Holstein y niveles séricos de estradiol y tiroxina. Rev. Electrón. Vet. 11 (1). Disponible desde Internet en: http://www.veterinaria.org/revistas/redvet/n010110/011001.pdf (con acceso 12/03/2013).

27 NUESSLY, G. 2011. Yellow Sugarcane Aphid, Sipha flava (Forbes) (Insecta Hemiptera Aphididae). University of Florida IFAS Extension EENY 354. Disponible desde internet en: http://edis.ifas.ufl.edu/in635 (con acceso 12/03/2013).

28. PATIÑO, V. 1969. Plantas cultivadas y animales domésticos en América Equinoccial. Tomo IV: Plantas introducidas. Cali, Colombia, Imprenta Departamental. Disponible desde internet en: http://www.banrepcultural.org/blaavirtual/historia/puti/puti1.htm (Con acceso 25/03/2013).

29. POSADA O., L. 1989. Lista de insectos plagas registrados en Colombia. Instituto Colombiano Agropecuario. Boletín Técnico No. 43. Bogotá, Colombia. 662p.

30. RIVERA-POSADA, J.H. 1998. Control de cárcavas remontantes en zonas de ladera mediante tratamientos biológicos. Cenicafé. Avances Técnicos. 256:8. 
31. SAS INSTITUTE. 2006. SAS user's guide: statistics, version. 9.1.3. SAS Institute, Cary, NC.

32. SIMBAQUEBA, R.; SERNA, F.; POSADA-FLOREZ, F.P. 2014. Curaduría, morfología e identificación de áfidos (Hemiptera: Aphididae) del Museo Entomológico UNAB. Primera aproximación. En prensa: Boletín de Museos de la Universidad de Caldas.

33. STOETZEL, M.B. 1987. Information on and identification of Diuaraphis noxia (Homoptera: Aphidae) and other aphid species colonizing leaves of wheat in the United States. J. Econ. Entomol. 80:696-704.
34. TEETES, G.; PENDLETON, B.B. 2000. Insect pests of sorghum. In: Smith, C.W.; Frederiksen, R.A. (eds). Sorghum: origin, history, technology, and production. John Wiley \& Sons, Inc., New York, N.Y. 840p.

35 VICTORIA, J.; GUZMÁN, M.L.; CUERVO, E.; LOCKHART, B. 1999. Síndrome de la hoja amarilla en Colombia. Cenicaña. Serie divulgativa No 07. 4p. Disponible desde internet en: http://www.cenicana.org/publicaciones/serie_divulgativa/serie_div_7.php (con acceso $12 / 03 / 2013)$.

Recibido: Septiembre 23 de 2013

Aceptado: Abril 10 de 2014

\section{Como citar:}

Posada-Flórez, F.J.; Téllez-Farfán, L.; Simbaqueba, R.; Serna, F. 2014. Reconocimiento y observaciones bionómicas de Sipha flava (Hemiptera: Aphididae) atacando el pasto kikuyo en dos zonas de Colombia. Rev. U.D.C.A Act. \& Div. Cient. 17(1): 95-104. 